\title{
Outbreak of Marek's disease in a vaccinated broiler breeding flock during its peak egg-laying period in China
}

\author{
Xinyu Zhuang ${ }^{1}$, Haitao Zou ${ }^{1}$, Huoying Shi ${ }^{1,2,3}$, Hongxia Shao ${ }^{1,2,3}$, Jianqiang Ye ${ }^{1,2,3}$, Ji Miao ${ }^{2}$, Genghua Wu ${ }^{2}$
} and Aijian Qin ${ }^{1,2,3^{*}}$

\begin{abstract}
Background: Outbreaks of Marek's disease (MD), caused by Marek's disease virus (MDV), primarily occur in 10-12-week-old hens.

Case presentation: We report a case of MD in a breeding flock of 24-30-week-old vaccinated broilers in China. The clinical signs in the affected chickens appeared at 24 weeks, and the incidence of tumours peaked at 30 weeks. The morbidity and mortality of the hens were $5 \%$ and $80 \%$, respectively. Hematoxylin-eosin staining of the tissues showed the typical characteristics of MD. MDV infection was confirmed in the hens with an agar gel diffusion precipitation assay for the MD antigen in the feather follicle epithelium. An MDV strain, designated AH1410, was isolated from the blood lymphocytes. Sequence analyses of the $p p 38$, meq, and $g B$ genes revealed that strain AH1410 had molecular features consistent with a virulent, previously identified MDV.

Conclusion: Our data provide evidence that not only is MDV becoming more virulent, but that the period of its onset in chickens is expanding. These findings provide the basis the molecular surveillance and further study of virulent MDV mutants and control strategies for MD in China.
\end{abstract}

Keywords: Marek's disease virus, Isolation, Gene analysis, Broiler breeding chicken, peak egg-laying period

\section{Background}

Marek's disease (MD) is caused by Marek's disease virus (MDV), of the family Herpesviridae. MD was first reported in 1907 by Josef Marek and is characterised by T-cell lymphomas in the peripheral nerves or organs of 10-12week-old hens [1]. MDV is currently distributed worldwide. Although vaccination plays a vital role in the prevention and control of MD globally, MDVs of increased virulence have been frequently isolated in some countries, even among vaccinated chickens, calling into question the current vaccination program against MDVs. The virulent MDVs (vMDVs) usually carry mutations in genes such as

\footnotetext{
* Correspondence: aijian@yzu.edu.cn

${ }^{1}$ Ministry of Education Key Laboratory for Avian Preventive Medicine, Yangzhou University, No. 12 East Wenhui Road, Yangzhou, Jiangsu 225009, P.R. China

${ }^{2}$ Key Laboratory of Jiangsu Preventive Veterinary Medicine, Yangzhou University, Yangzhou 225009, P.R. China

Full list of author information is available at the end of the article
}

pp38, meq, or $g B$, that are associated with the oncogenicity and and their immune evasion [2,3].

In China, a vaccine has been widely used to prevent $M D$ in the poultry industry. However, the MD vaccine program has frequently failed, and vMDVs are occasionally isolated in vaccinated chickens [4]. In this study, we report a recent outbreak of MD in a vaccinated breeding broiler flock in China during its peak egg-laying period.

\section{Case presentation}

Clinical symptoms and pathological lesions

The sick chickens were obtained from a large farm in Anhui Province, China. The owner of the chickens gave permission for their animals to be included in this study. The chickens were 24-30 weeks old. Tumours were found in their organs and skin. The occurrence of tumours increased progressively and reached its highest level (5\%) during the peak egg-laying period (30 weeks old), after which it began to decline. In the majority of 
sick chickens, the cysts first appeared between the toes (Fig. 1a) and then in the tarsometatarsus. All the chickens were hens. Tumours were observed in almost all tissues, particularly the liver (Fig. 1b). Immature infiltrated lymphocytes were observed in the liver and spleen during the histopathological diagnosis, ultimately destroying the tissue structure. Most of the darkly stained cells were lymphocytes, among which red eosinophilic granules were spotted. Many multinucleate cells with infiltrated lymphoid cells were present in the compartment of the liver (Fig. 1c), corresponding to the classical lesions of MDV.

\section{MDV antigen found in feathers}

A band of MDV antigen was precipitated from the feather epithelia of the sick chickens. However, no band representing MDV antigen was found in the sera of the sick chickens. This suggests that the feather tips of the chickens excrete MDV particles. The anti-MDV antibody titres in the sera of the chickens were too low to detect with the agar gel diffusion precipitation (AGP) assay.

\section{Isolation and identification of MDV in the flock}

After two blind passages of chicken embryo fibroblast (CEF) cells, the presence of MDV (designated strain AH1410) in the CEF was confirmed when the typical cytopathic effect (CPE) appeared on the third day after infection (Fig. 2a). The infected cells became round and were highly refractive. When the cells were analysed with an anti-gB monoclonal antibody (Mab) BA4, specific uniform fluorescence was observed in both the nuclei and cytoplasm of the infected cells, but not in the CEF, suggesting that the cells showing the CPE reacted with the MDV-1 gB-specific Mab BA4 (Fig. 2b).

\section{MDV isolate has molecular features of vMDVs}

The genomic DNA was extracted from CEF infected with the isolated virus. The complete sequences of the $m e q, g B$, and $p p 38$ genes were successfully amplified with PCR (Fig. 3a). A sequence analysis revealed that the pp38 gene of AH1410 shared $99.3 \%-100.0 \%$ identity with those of reference strains, with only a single amino acid mutation at position $109(\mathrm{E} \rightarrow \mathrm{G})$ in the deduced amino acid sequence (Fig. $3 b$ ). When we compared the meq sequences of reference strains published in the National Center for Biotechnology Information database with that of isolate AH1410, we found an insertion of 59 amino acids at position 194 of MEQ in the vaccine strain CVI988, so that its ORF encodes 398 amino acids. However, isolate AH1410 and other vMDVs all have ORFs encoding 339 amino acids in their meq genes, with $99.7 \%-100.0 \%$ homology. Only four amino acid mutations, at residues $80(\mathrm{D} \rightarrow \mathrm{Y}), 115(\mathrm{~V} \rightarrow \mathrm{A}), 139$ $(\mathrm{T} \rightarrow \mathrm{A})$, and $176(\mathrm{P} \rightarrow \mathrm{R})$, were found in isolate AH1410, which are identical to those in strain GX0101 (Fig. 3c). Analysis of the $g B$ gene indicated that it was $100.0 \%$ homologous between isolate AH1410 and other MDVs, with no mutations.

\section{Discussion}

Marek's disease is one of the most significant infectious diseases in poultry. In birds, it can result in tumours or immunosuppression, making the birds more sensitive to other pathogens. Although MD vaccines have been widely used in China for a long time, failures of MD vaccination occur frequently on some poultry farms. The improper selection of a vaccine could be the cause of vaccine failure [5]. Birds are also more susceptible to MDV mutants that have emerged in regions with morevirulent strains than to previous MDV isolates.

The $p p 38$ gene encodes a phosphoprotein of approximately $38 \mathrm{kDa}$ that is necessary for both cell transformation and viral reactivation in the latent period $[6,7]$. The $p p 38$ gene is conserved in all strains of MDV so far isolated. Previously, it was believed that pp38 was not present in MDV strain CVI988 [8], but in recent years, the gene was shown to be expressed by CV1988, and a mutation at residue $107(\mathrm{Q} \rightarrow \mathrm{R})$ is identified with $\mathrm{Mab}$ H19 $[9,10]$. In this study, we found no mutation at residue 107 of the PP38 protein of the isolated strain

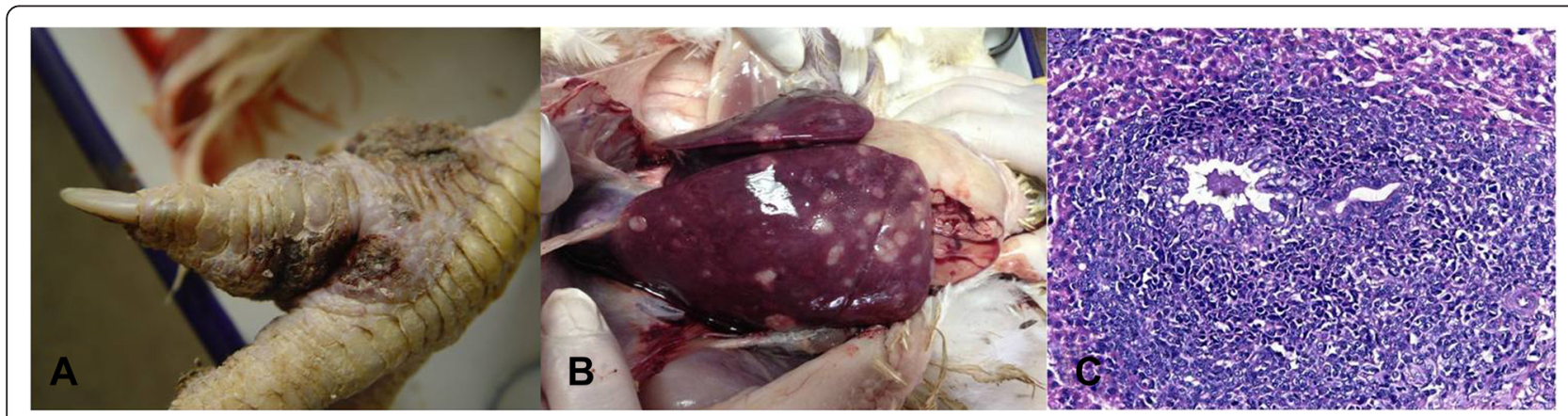

Fig. 1 Clinical symptoms and pathological lesions. a: Cysts appeared in the toes; b: tumors appeared in the liver; c: histopathological tissue (HE, 400X) 


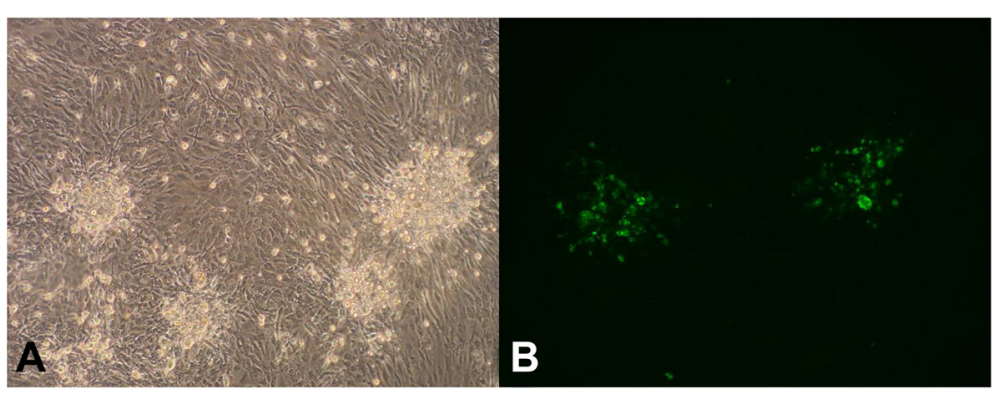

Fig. 2 Viruses in CEF cells and indirect immunofluorescence assay with an MAb directed against MDV. a: MDV CPE in the CEF; b: immunofluorescence-positive cells tested with MAb BA4 against MDV-1

AH1410. The $p p 38$ gene sequence was identical to that of the vMDVs. However, at residue 109 of pp38 in the vMDVs and the very virulent MDVs (vvMDVs), such as strains GA, MD5, and RB1B, glutamate is replaced by glycine, which differs from the sequence of strain AH1410, which is similar to that of other virulent viruses isolated in
China, such as GX0101 and JS0711. Therefore, the isolated virus $\mathrm{AH} 1410$ is not the vaccine strain.

The MEQ protein, which is considered to be the major factor responsible for the occurrence of tumours, contains 339 amino acids [4]. However, the meq gene of CVI988 has an insertion of $177 \mathrm{bp}$ compared with the genes of the

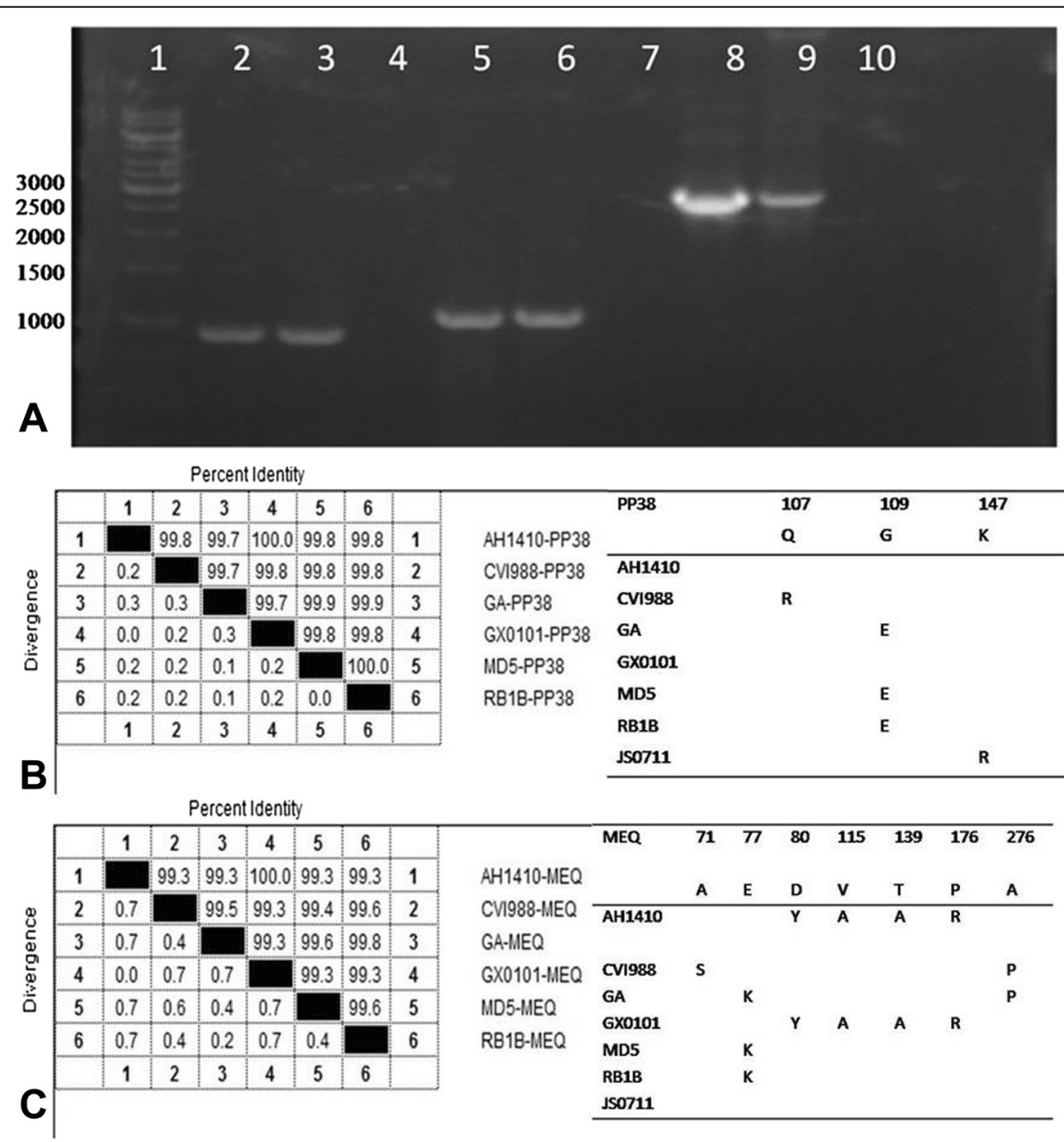

Fig. 3 MDV genes amplified with PCR and the corresponding homology analyses. a: PCR results for the mea, $p p 38$, and $g B$ genes. Lane 1: 1-kb marker; lanes 4, 7, 10: negative controls; lanes 2 and 3: amplified mea gene; lanes 5 and 6: amplified pp38 gene; lanes 8 and 9: amplified gB gene. b: Homology analysis and mutations of pp38. c: Homology analysis and mutations of mea 
vMDVs, which results in a 59-amino-acid insertion relative to the MEQ proteins of the vMDVs [11-13], that inhibits the expression of the meq gene [14]. Research has also indicated that mutations at positions 71 and 77 of the MEQ protein could be distinct in the vvMDVs [15]. Compared with CVI988, position 71 of strain AH1410 is mutated $(\mathrm{S} \rightarrow \mathrm{A})$, as in the vMDVs, whereas position 77 is conserved. No deletion or insertion was found at position 194 and the ORF of AH1410 meq encodes 339 amino acids. We also found mutations at positions 80, 115, 139, and 176 of MEQ in our isolate AH1410, similar to those in GX0101 [16], suggesting that this type of strain has been circulating in China for many years.

With sequence alignments of the meq, $p p 38$, and $g B$ genes of strain AH1410 and other MDV isolates, we found that GX0101 and AH1410 are completely identi$\mathrm{cal}$ in these three genes. A previous study demonstrated that the virulence of GX0101 was at a level between those of GA and Md5 [16]. Collectively, these data indicate that the pathogenicity of isolate AH1410 may be similar to that of isolate GX0101.

The mutations and increasing virulence of MDV are thought to be responsible for the occurrence of MD on vaccinated farms. The failure of MD vaccination may be one reason for the outbreak reported here. Notably, the onset of MD in broilers generally starts at 4-6 weeks of age. In hens, MD usually occurs at 10-12 weeks of age [17]. However, in this case, the rate of tumours reached its highest level during the peak egg-laying period (30 weeks old).

Outbreaks among egg-laying chickens have also been reported in the mining area of Karnataka, India [18], and excessive losses from MD have recently been reported in adult laying flocks over the age of 40 weeks in Japan [19]. The data indicate that these birds may have contracted these infections later in life, with subsequent clinical signs. We also found that the feathers of the chickens were positive for the virus, whereas their sera were negative for MDV antigen, indicating that the chickens' immune responses may have been suppressed in other ways, an unusual phenomenon and a disquieting trend. Another interesting observation is that all the diseased chickens were hens, which is consistent with an observation by Heier et al., who noted that males tended to be more resistant to MD than females [20].

It is necessary to strengthen the surveillance of circulating MDVs because new variants of virulent MDVs may appear at any time, and better vaccines against MD must be developed.

\section{Conclusion}

Our data provide evidence that not only is MDV becoming more virulent, but that the period of its onset in chickens is also expanding. These findings provide the basis for the molecular surveillance of MDV, and further study of its virulence mutants and the control strategies required for MDV in China.

\section{Methods \\ Chickens and samples}

All the chickens were obtained from a breeding broiler chicken farm in Anhui, China. The chickens were immunized with the CVI988 vaccine at 1 day old. This vaccine had been used on the chicken farm for many years by skilled workers who vaccinate the chickens according to standard procedures. The clinical symptoms presented between 24 and 30 weeks. The morbidity and mortality of the hens were $5 \%$ and approximately $80 \%$, respectively. Samples were obtained from the sick chickens. Avian leukosis virus and Reticuloendotheliosis virus infections were detected with PCR and virus isolation in our initial pathogen screening. The chickens reported here were negative for both viruses. All the experiments complied with institutional animal care guidelines and were approved by the University of Yangzhou Animal Care Committee.

\section{Histochemical assay}

A histopathological assay and hematoxylin-eosin (HE) staining of the tissues were performed as previously described [21]. In brief, the livers and spleens of the sick chickens were fixed in $10 \%$ neutral formalin, dehydrated in alcohol, and embedded in paraffin. They were then stained with HE and screened with light microscopy.

\section{AGP assay}

An AGP test was performed on $1 \%$ agar plates containing $8 \% \mathrm{NaCl}$. In the AGP test, CEF cells infected with MDV strain RB1B were used as the positive control antigen, and preserved sera from the MDV-infected chickens were used as the positive control sera. The positive antigen $(20 \mu \mathrm{l})$ was placed in the central well, and the same volumes of positive sera and samples were placed in the surrounding wells. The feather follicle epithelium was tested for the presence of MDV antigen. The plates were then placed in a humidified cabinet at $37^{\circ} \mathrm{C}$, and the precipitation lines were examined after $72 \mathrm{~h}$.

\section{Virus isolation}

Lymphocytes were separated with Lymphocyte Separation Medium (Tianjin Haoyang Biological Manufacture Co., Ltd) from the anticoagulant blood samples collected from the chickens. Primary CEF cultures were prepared from 10-day specific-pathogen-free embryos and inoculated in six-well plates with Dulbecco's modified Eagle's medium (DMEM) containing $5 \%$ foetal bovine serum (FBS) in a total volume of $2 \mathrm{ml}$ and incubated for $24 \mathrm{~h}$. Then $60 \mu \mathrm{l}$ of lymphocytes was added to the six-well plates that had been spread with the CEF. The plates 
Table 1 Primers used to amplify MDV genes

\begin{tabular}{llll}
\hline Target & Name & Sequence & Length \\
\hline pp38 & pp38-F & 5-AATGGATCCATGGAATTCGAAGCAGAAC-3 & 903 bp \\
& pp38-R & 5-ATTGTCGACAACATCGGGTACGGCTAC-3 & \\
meq & meq-F & 5-CGCGAATTCTACAGGTGTAAAGAGATG-3 & 1058 bp \\
& meq-R & 5-TAACTCGAGTGCTGAGAGTCACAATGC-3 & \\
gB & gB-F & 5-CAGTCGACTATGCACTATTTAG-3 & $2.8 \mathrm{~kb}$ \\
& gB-R & 5-CAGGAATTCACAAGGAAAGCATCG-3 & \\
\hline
\end{tabular}

were incubated at $37{ }^{\circ} \mathrm{C}$ in $5 \% \mathrm{CO}_{2}$. After $24 \mathrm{~h}$, the DMEM was replaced with DMEM maintenance medium containing $1 \%$ FBS. The plates were then incubated in a culture chamber for 6 days with 2-3 blind passages.

\section{Indirect immunofluorescence assay}

The CEF with CPE were fixed with acetone: ethanol solution (3:2) for $10 \mathrm{~min}$ and washed once with PBS. After the fixed cells were blocked with $1 \%$ BSA in PBS, they were incubated with the MDV-specific Mab BA4 [22] for $30 \mathrm{~min}$ at $37^{\circ} \mathrm{C}$. After three washes with PBS, the cells were incubated with fluorescein isothiocyanate (FITC)conjugated goat anti-mouse antibody (Sigma-Aldrich, USA) for another $30 \mathrm{~min}$. After three washes with PBS, the cells were examined under a fluorescence microscope.

\section{PCR and sequence analysis}

The $m e q, p p 38$, and $g B$ genes of the isolates were amplified with the primers listed in Table 1. The DNA extracted from CEF infected with the isolate was used as the template. In the PCR system, $50 \mu \mathrm{l}$ of reaction volume was used, consisting of $5 \mu \mathrm{l}$ of $10 \times L A$ Taq PCR buffer, $2 \mu \mathrm{l}$ each of the two primers, $0.5 \mu \mathrm{l}$ of $L A$ Taq DNA polymerase, $38.5 \mu \mathrm{l}$ of $\mathrm{ddH}_{2} \mathrm{O}$, and $2 \mu \mathrm{l}$ of the DNA template. The PCR parameters for the $p p 38$ and $m e q$ genes were: $95{ }^{\circ} \mathrm{C}$ for $5 \mathrm{~min}$, 30 cycles of $94{ }^{\circ} \mathrm{C}$ for $60 \mathrm{~s}, 55^{\circ} \mathrm{C}$ for $60 \mathrm{~s}$, and $72{ }^{\circ} \mathrm{C}$ for $60 \mathrm{~s}$, and then $72{ }^{\circ} \mathrm{C}$ for $10 \mathrm{~min}$. The PCR parameters for the $g B$ gene were: $95{ }^{\circ} \mathrm{C}$ for $5 \mathrm{~min}, 30$ cycles of $94{ }^{\circ} \mathrm{C}$ for $60 \mathrm{~s}, 55^{\circ} \mathrm{C}$ for $60 \mathrm{~s}$, and $72{ }^{\circ} \mathrm{C}$ for $2 \mathrm{~min}$, and then $72{ }^{\circ} \mathrm{C}$ for $10 \mathrm{~min}$. The PCR products were separated on a $1 \%$ DNA gel and then sequenced by Genscript (Nanjing, China). All the sequences were aligned and analysed with DNAStar.

\section{Abbreviations \\ MD: Marek's disease; MDV: Marek's disease virus; AGP: agar gel diffusion precipitation; CEF: chicken embryo fibroblast; FBS: foetal bovine serum; DMEM: Dulbecco's modified Eagle's medium; CPE: cytopathic effect; BSA: bovine serum albumin; FITC: fluorescein isothiocyanate; $\mathrm{PCR}$ : polymerase chain reaction.}

\section{Competing interests}

The authors declare that they have no competing interests.

\section{Authors' contributions}

$X Y Z$ carried out the molecular genetic studies, the immunoassays, AGP test and Virus isolation, participated in the sequence alignment and drafted the manuscript. HYS carried out the histochemistry assay. HTZ participated in the sequence alignment. AJQ designed the study, analyzed the results and drafted the manuscript. JQY, HXS discussed and revised the manuscript. JM and GHW conceived of the study, and participated in its design and coordination. All authors read and approved the final manuscript.

\section{Acknowledgements}

This research was supported by the National Natural Science Foundation of China (31472192), the Major Basic Research Department of the Natural Science Foundation of Jiangsu Higher Education Institutions of China (grant no. 12KJA23001), and the Priority Academic Program Development of Jiangsu Higher Education Institutions.

\section{Author details}

'Ministry of Education Key Laboratory for Avian Preventive Medicine, Yangzhou University, No. 12 East Wenhui Road, Yangzhou, Jiangsu 225009, P.R. China. ${ }^{2}$ Key Laboratory of Jiangsu Preventive Veterinary Medicine, Yangzhou University, Yangzhou 225009, P.R. China. ${ }^{3}$ Jiangsu Co-innovation Center for the Prevention and Control of Important Animal Infectious Diseases and Zoonoses, Yangzhou 225009, P.R. China.

Received: 19 January 2015 Accepted: 16 July 2015

Published online: 23 July 2015

\section{References}

1. Calnek BW. Pathogenesis of Marek's disease virus infection. Curr Top Microbiol Immunol. 2001;255:25-55.

2. Afonso CL, Tulman ER, Lu Z, Zsak L, Rock DL, Kutish GF. The genome of turkey herpesvirus. J Virol. 2001;75(2):971-8.

3. Lupiani B, Lee LF, Reddy SM. Protein-coding content of the sequence of Marek's disease virus serotype 1. Curr Top Microbiol Immunol. 2001;255:159-90.

4. Zhang YP, Liu CJ, Zhang F, Shi W, Li J. Sequence analysis of the Meq gene in the predominant Marek's disease virus strains isolated in China during 2006-2008. Virus Genes. 2011:43(3):353-7.

5. Gong Z, Zhang L, Wang J, Chen L, Shan H, Wang Z, et al. Isolation and analysis of a very virulent Marek's disease virus strain in China. Virol J. 2013;10:155.

6. Gimeno IM, Witter RL, Hunt HD, Reddy SM, Lee LF, Silva RF. The pp 38 gene of Marek's disease virus (MDV) is necessary for cytolytic infection of B cells and maintenance of the transformed state but not for cytolytic infection of the feather follicle epithelium and horizontal spread of MDV. J Virol. 2005;79(7):4545-9.

7. Ross NL. T-cell transformation by Marek's disease virus. Trends Microbiol. 1999;7(1):22-9.

8. Witter RL, Silva RF, Lee LF. New serotype 2 and attenuated serotype 1 Marek's disease vaccine viruses: selected biological and molecular characteristics. Avian Diseases. 1987;31(4):829-40.

9. Davidson I, Borovskaya A, Perl S, Malkinson M. Use of the polymerase chain reaction for the diagnosis of natural infection of chickens and turkeys with Marek's disease virus and reticuloendotheliosis virus. Avian Pathol. 1995;24(1):69-94.

10. Cui Z, Qin A, Lee LF, Wu P, Kung HJ. Construction and characterization of a H19 epitope point mutant of MDV CVI988/Rispens strain. Acta Virol. 1999;43(2-3):169-73.

11. Chang KS, Ohashi K, Onuma M. Diversity (polymorphism) of the meq gene in the attenuated Marek's disease virus (MDV) serotype 1 and MDVtransformed cell lines. J Vet Med Sci. 2002;64(12):1097-101.

12. Lee LF, Wu P, Sui D, Ren D, Kamil J, Kung HJ, et al. The complete unique long sequence and the overall genomic organization of the GA strain of Marek's disease virus. Proc Natl Acad Sci U S A. 2000;97(11):6091-6.

13. Spatz SJ, Petherbridge L, Zhao $Y$, Nair V. Comparative full-length sequence analysis of oncogenic and vaccine (Rispens) strains of Marek's disease virus. J Gen Virol. 2007:88(Pt 4):1080-96.

14. Chang KS, Ohashi K, Onuma M. Suppression of transcription activity of the MEQ protein of oncogenic Marek's disease virus serotype 1 (MDV1) by L-MEQ of non-oncogenic MDV1. J Vet Med Sci. 2002;64(12):1091-5.

15. Shamblin CE, Greene N, Arumugaswami V, Dienglewicz RL, Parcells MS Comparative analysis of Marek's disease virus (MDV) glycoprotein-, lytic antigen pp 38- and transformation antigen Meq-encoding genes: 
association of meq mutations with MDVs of high virulence. Vet Microbiol. 2004;102(3-4):147-67.

16. Zhang Z, Cui Z. Isolation of recombinant field strains of Marek's disease virus integrated with reticuloendotheliosis virus genome fragments. Sci China C Life Sci. 2005;48(1):81-8.

17. Okwor EC, Eze DC. Outbreak and Persistence of Marek's Disease in Batches of Birds Reared in a Poultry Farm Located in Nsukka, South East Nigeria. Int J Poult Sci. 2011;10(8):617-20.

18. Muniyellappa HK, Satyanarayana ML, Isloor S, Shivakumar Gowda NK. Marek's disease outbreak among vaccinated commercial layer flocks in the mining area of Karnataka, India. Vet Rec. 2013;172(17):452.

19. Ikezawa M, Goryo M, Sasaki J, Haridy M, Okada K. Late Marek's disease in adult chickens inoculated with virulent Marek's disease virus. J Vet Med Sci. 2010;72(12):1539-45,

20. Heier BT, Jarp J, Kaldhusdal MI, Schaller G, Forus IB. A longitudinal field study of mortality and Marek's disease in Norwegian and imported white Leghorns. Prev Vet Med. 1999;40(3-4):207-19.

21. Zhang W, Li Y, Lin J, Wan S, Gao H, Zhang L, et al. Comparison of hematoxylin-eosin staining and methyl violet staining for displaying ghost cells. Eye Sci. 2013;28(3):140-3.

22. Liu L, Qu Y, Wang T, Wang G, Wang F, Liu S. Skin involvement in lymphomas caused by Marek's disease virus infection in Silkie chickens. J Vet Diagn Invest. 2014;26(2):302-7.

\section{Submit your next manuscript to BioMed Central and take full advantage of:}

- Convenient online submission

- Thorough peer review

- No space constraints or color figure charges

- Immediate publication on acceptance

- Inclusion in PubMed, CAS, Scopus and Google Scholar

- Research which is freely available for redistribution 